\title{
Living Cationic Polymerization of tert-Butyl Vinyl Ether by Organoaluminum Halides in the Presence of Added Bases
}

\author{
Sadahito Aoshima, Kenji Shachi, and Eiichi Kobayashi* \\ Department of Industrial Chemistry, Faculty of Science and Technology, \\ Science University of Tokyo, Noda, Chiba 278, Japan
}

(Received August 16, 1993)

\begin{abstract}
Living cationic polymerization of tert-butyl vinyl ether (TBVE) was achieved by the 1-(isobutoxy)ethyl acetate (1)/Et $\mathrm{Et}_{1.5} \mathrm{AlCl}_{1.5}$ initiating system in the presence of THF in hexane at $-20^{\circ} \mathrm{C}$. The polymers had a very narrow molecular weight distribution $\left(\bar{M}_{w} / \bar{M}_{n} \leq 1.1\right)$, and $\bar{M}_{n}$ increased directly proportional to the monomer conversion. On the other hand, under conditions suitable for the living polymerization of isobutyl vinyl ether (e.g., $1 / \mathrm{EtAlCl}_{2}$ initiating system, methyl acetate as added base, temperatures higher than $0^{\circ} \mathrm{C}$ ), non-living polymers of TBVE with a broader molecular weight distribution were obtained. For the living polymerization of such a highly reactive monomer as TBVE, combinations of added bases having stronger basicity, weaker Lewis acid activators, and low temperature turned out to be indispensable. Using this system, the high molecular weight poly(TBVE) with a narrow molecular weight distribution was also obtained $\left(\bar{M}_{n}=1.1 \times 10^{5}, \bar{M}_{w} / \bar{M}_{n}=1.11\right)$. The tert-butyl groups of the poly(TBVE) were quantitatively deprotected $(99.9 \%$ ) by bubbling $\mathrm{HBr}$ gas, to yield poly(vinyl alcohol). To elucidate the polymerization characteristics of TBVE, neo-pentyl vinyl ether and three isomers of butyl vinyl ethers ( $n$-butyl vinyl ether, isobutyl vinyl ether, and sec-butyl vinyl ether) were polymerized, and polymerization behavior is discussed on the basis of the sterical structures of side alkyl groups.

KEY WORDS Living Cationic Polymerization / tert-Butyl Vinyl Ether / Isomers of Butyl Vinyl Ethers / neo-Pentyl Vinyl Ether / Added Base / Tetrahydrofuran / Organoaluminum Halides / $\mathrm{Et}_{1.5} \mathrm{AlCl}_{1.5}$ / High Molecular Weight Polymers / Poly(vinyl alcohol) /
\end{abstract}

Living polymerizations of vinyl monomers used for the preparation of water-soluble polymers have been very difficult so far, because the polar substituents cause often various side reactions during the polymerization. In our laboratory, to synthesize poly(vinyl alcohol) (PVA) with a narrow molecular weight distribution (MWD) and its block copolymers, living cationic polymerizations of benzyl vinyl ether ${ }^{1}$ and tert-butyl-dimethylsilyl vinyl ether, ${ }^{2}$ and dealkylation or desilylation reactions of the polymers to alcohol group have been extensively investigated. These living cationic polymerizations were achieved by the use of externally added bases for the stabilization of unstable growing carbocations. ${ }^{3}$

Living polymerizations of tert-butyl vinyl ether (TBVE), of which polymer is a precursor of PVA, ${ }^{4}$ have not been yet examined, whereas stereospecific polymerization ${ }^{5,6}$ and the reactivity of $\mathrm{TBVE}^{7}$ have been studied in detail. In this paper, the possibility of living cationic polymerization of TBVE was examined. First, to establish suitable living polymerization conditions, the effects of polymerization temperatures, basicity of added bases, and acid strength of Lewis acid activators were studied. To make clear differences in polymerization

\footnotetext{
* To whom all correspondence should be addressed.
} 
behavior between TBVE and other vinyl ethers, steric effects of the side alkyl groups were investigated by use of neo-pentyl vinyl ether (NPVE) and three isomers of butyl vinyl ethers as monomers having a variety of steric environments.

\section{EXPERIMENTAL}

\section{Materials}

Commercial isobutyl vinyl ether (IBVE, Tokyo Kasei Co.) and $n$-butyl vinyl ether (NBVE, Wako Chemical Co.) were washed with an aqueous alkaline solution and water, and then distilled twice over calcium hydride. ${ }^{3}$ TBVE, NPVE, and sec-butyl vinyl ether (SBVE) were prepared by the transetherification between octadecyl vinyl ether (Tokyo Kasei Co.) and the corresponding alcohols in the presence of mercuric acetate catalyst. ${ }^{8}$ The crude products were washed with a dilute aqueous alkaline solution, and then dried over potassium hydroxide. After reflux over calcium hydride for $6 \mathrm{~h}$ and then over sodium hydride for $6 \mathrm{~h}$, the crude monomers were distilled over sodium hydride at least twice. $\mathrm{EtAlCl}_{2}$ (Nippon Aluminum Alkyls Co.) was distilled under reduced pressure. $\mathrm{Et}_{1.5} \mathrm{AlCl}_{1.5}$ was prepared by mixing $\mathrm{EtAlCl}_{2}$ with equimolecular amounts of $\mathrm{Et}_{2} \mathrm{AlCl}$ (Nippon Aluminum Alkyls Co.) at room temperature for $8 \mathrm{~h}$, and then distilled under reduced pressure. Hexane as a polymerization solvent was purified by the usual method and distilled at least twice over calcium hydride just before use. ${ }^{3}$ Methyl acetate (Wako Chemical Co.) and tetrahydrofuran (THF) (Nacalai Tesque Co.) were distilled over calcium hydride and metallic sodium, respectively. 1-(Isobutoxy)ethyl acetate (1) was prepared from IBVE and acetic acid as previously reported, ${ }^{3}$ and distilled twice over calcium hydride under a reduced pressure.

\section{Procedures}

Polymerization was carried out at 0 and $-20^{\circ} \mathrm{C}$ under dry nitrogen atmosphere in a baked glass tube equipped with a three-way stopcock. The reaction was initiated by the addition of an $\mathrm{EtAlCl}_{2}$ or $\mathrm{Et}_{1.5} \mathrm{AlCl}_{1.5}$ solution in hexane into a mixture of the monomer, an added base, and the cationogen 1 in hexane at the polymerization temperature. After a proper interval, the polymerization was quenched with $0.25 \mathrm{wt} \%$ ammoniac methanol. The quenched reaction mixture was sequentially washed with dilute hydrochloric acid $(0.6 N)$ and water to remove the initiator residues, and then neutralized with a dilute aqueous sodium hydroxide solution. The product polymer was recovered from the organic layer by evaporation of the monomer and solvent under reduced pressure and vacuum dried overnight. Conversion of the monomer was measured by gravimetry.

\section{Measurements}

The molecular weight distribution (MWD) of the polymers was measured by size-exclusion chromatography (SEC) in chloroform at $40^{\circ} \mathrm{C}$ on a CCPD instrument (Tosoh Co.) equipped with four polystyrene gel columns (TSK gel G-2000, 3000, and $4000 \times 2$; inner diameter: $8.0 \mathrm{~mm}$, length: $300 \mathrm{~mm}$, each) and a refractive index detector. The number-average molecular weight $\left(\bar{M}_{n}\right)$ and polydispersity $\left(\bar{M}_{w} / \bar{M}_{n}\right)$ were calculated from the SEC curves on the basis of a polystyrene calibration.

\section{RESULTS AND DISCUSSION}

\section{Living Cationic Polymerization of TBVE}

The polymerization of TBVE was first carried out under similar conditions where the living cationic polymerization of IBVE was achieved $^{3}$; i.e., initiating system: $1 / \mathrm{EtAlCl}_{2}$, added base: methyl acetate, solvent: hexane, temperature: $0^{\circ} \mathrm{C}$. The polymerization of TBVE proceeded at such a faster rate [see Figure $1(\triangle)$ ] to give quantitative conversion within $0.2 \mathrm{~h}$ ( $7 \mathrm{~h}$ for IBVE). Figure 2 shows the relationships between the monomer conversion and $\bar{M}_{n}$ or MWD of the product polymers of 


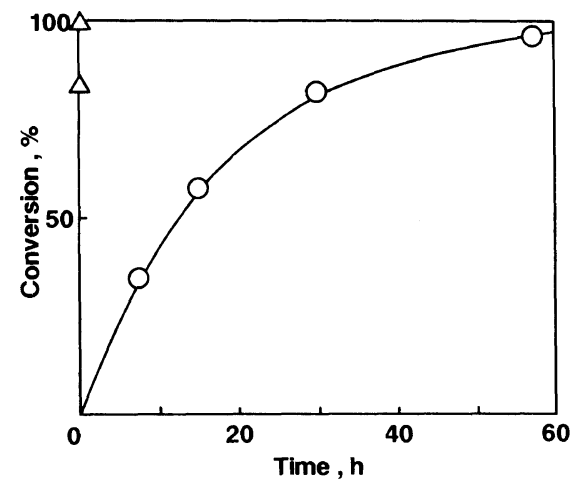

Figure 1. Time-conversion curves for the polymerization of TBVE by $1 / \mathrm{Et}_{x} \mathrm{AlCl}_{3-x}$ in the presence of added bases $(1.0 \mathrm{M})$ in hexane: $[\text { TBVE }]_{0}=0.76 \mathrm{M},[1]_{0}=4.0 \mathrm{mM}$. (O) added base: THF, $\left[\mathrm{Et}_{1.5} \mathrm{AlCl}_{1.5}\right]_{0}=20 \mathrm{mM}$, at $-20^{\circ} \mathrm{C}$; $(\triangle)$ methyl acetate, $\left[\mathrm{EtAlCl}_{2}\right]_{0}=20 \mathrm{mM}$, at $0^{\circ} \mathrm{C}$.

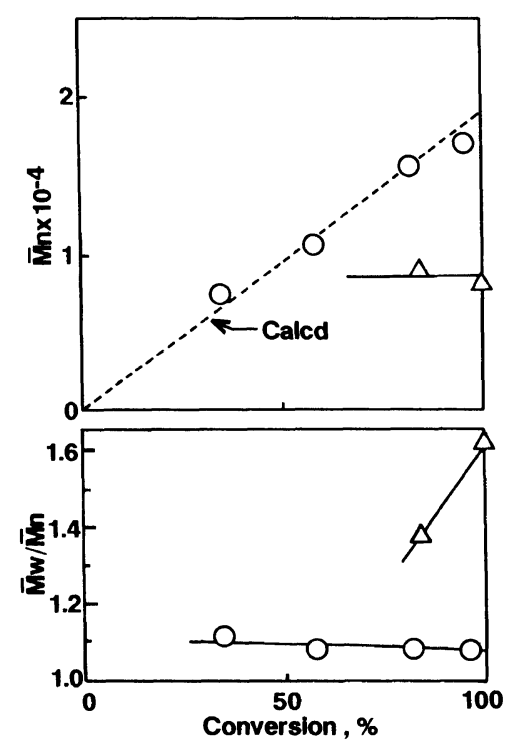

Figure 2. Relationships between monomer conversion and $\bar{M}_{n}$ or $\bar{M}_{w} / \bar{M}_{n}$ of polymers in the polymerization of TBVE by $1 / \mathrm{Et}_{1.5} \mathrm{AlCl}_{1.5}$ in the presence of THF (1.0 M) in hexane at $-20^{\circ} \mathrm{C}$ or by $1 / \mathrm{EtAlCl}_{2}$ in the presence of methyl acetate $(1.0 \mathrm{M})$ in hexane at $0^{\circ} \mathrm{C}$; polymerization conditions and symbols: see Figure 1.

TBVE. As shown in Figure $2(\triangle)$, MWD of the polymers of TBVE was broad $\left(\bar{M}_{w} / \bar{M}_{n}=\right.$ 1.63) and $\bar{M}_{n}$ did not increase with the monomer conversion. It was found that the polymerization behavior of TBVE was differ- ent from that of IBVE, and it was suggested that in the case of TBVE the side reactions such as chain transfer reactions occur frequently.

The polymerization of TBVE was also carried out by the $1 / \mathrm{Et}_{1.5} \mathrm{AlCl}_{1.5}$ initiating system in the presence of THF in hexane at $-20^{\circ} \mathrm{C}$, where the weak Lewis activitor, $\mathrm{Et}_{1.5} \mathrm{AlCl}_{1.5}$, added base having stronger basicity, THF, and low temperature, $-20^{\circ} \mathrm{C}$, were selected to depress the chain transfer reaction. Figure $1(\bigcirc)$ shows the timeconversion curve. The polymerization proceeded without an induction period up to the quantitative yield for $60 \mathrm{~h}$. In addition to the quite narrow $\operatorname{MWD}\left(\bar{M}_{w} / \bar{M}_{n}=1.08\right.$ at $96 \%$ conv.), $\bar{M}_{n}$ were directly proportional to the monomer conversion and were in good agreement with the calculated values, as shown in Figure 2(O).

To find suitable conditions for the living polymerization of TBVE, the effects of temperature, acid strength of activators, ${ }^{9,10}$ and basicity of added bases ${ }^{2,11}$ were investigated in detail. Table I summarizes the polymerization results under various conditions. As shown in No. 5 in Table I, the polymerization by the $1 / \mathrm{Et}_{1.5} \mathrm{AlCl}_{1.5}$ initiating system in the presence of THF at $-20^{\circ} \mathrm{C}$ gave the living poly(TBVE): the polymers' MWD became very narrow $\left(\bar{M}_{w} / \bar{M}_{n} \leq 1.1\right)$ and $\bar{M}_{n}$ was in agreement with the calculated value assuming the formation of one polymer chain per unit 1. In contrast, at $0^{\circ} \mathrm{C}$ (No. 1) or in the presence of methyl acetate (No. 2 and 3), MWDs of the polymers were broader $\left(\bar{M}_{w} /\right.$ $\left.\bar{M}_{n}=1.2-1.6\right)$. The use of $\mathrm{EtAlCl}_{2}$ as an activator (No. 4) caused serious decrease in $\bar{M}_{n}$ of the polymer even in the presence of $\mathrm{THF}^{10}$ at $-20^{\circ} \mathrm{C}$. It should be emphasized that for the living polymerization of TBVE, careful selection of the low temperature $\left(-20^{\circ} \mathrm{C}\right)$, weak Lewis acid activator $\left(\mathrm{Et}_{1.5} \mathrm{AlCl}_{1.5}\right)$, and added base having stronger basicity (THF) were indispensable.

The long lifetime of growing species was 
Table I. Polymerization of TBVE by $1 / \mathrm{Et}_{x} \mathrm{AlCl}_{3-x}$ in the presence of added bases ${ }^{\mathrm{a}}$

\begin{tabular}{|c|c|c|c|c|c|c|c|c|c|}
\hline \multirow{2}{*}{ No. } & \multicolumn{4}{|c|}{ Polymerization conditions } & \multicolumn{5}{|c|}{ Results } \\
\hline & Temp. $/{ }^{\circ} \mathrm{C}$ & Activator & Added base & Time $/ \mathrm{h}$ & Conv. $/ \%$ & $\bar{M}_{n}(\mathrm{Obd})$ & $\bar{M}_{n}($ Calcd $)$ & $\bar{M}_{w} / \bar{M}_{n}$ & Remark $^{b}$ \\
\hline 1 & 0 & $\mathrm{EtAlCl}_{2}$ & $\mathrm{CH}_{3} \mathrm{COOCH}_{3}$ & 0.2 & 100 & 8300 & 19000 & 1.63 & $x$ \\
\hline 2 & -20 & $\mathrm{EtAlCl}_{2}$ & $\mathrm{CH}_{3} \mathrm{COOCH}_{3}$ & 1.0 & 100 & 12300 & 19000 & 1.26 & $\triangle$ \\
\hline 3 & -20 & $\mathrm{Et}_{1.5} \mathrm{AlCl}_{1.5}$ & $\mathrm{CH}_{3} \mathrm{COOCH}_{3}$ & 1.0 & 97 & 15300 & 18400 & 1.23 & $\overline{0}$ \\
\hline 4 & -20 & $\mathrm{EtAlCl}_{2}$ & THF & 22.0 & 96 & 10900 & 18200 & 1.09 & 0 \\
\hline 5 & -20 & $\mathrm{Et}_{1.5} \mathrm{AlCl}_{1.5}$ & THF & 57.0 & 96 & 17100 & 18200 & 1.08 & () \\
\hline
\end{tabular}

${ }^{a}[\mathrm{TBVE}]_{0}=0.76 \mathrm{M},[1]_{0}=4.0 \mathrm{mM},\left[\mathrm{Et}_{x} \mathrm{AlCl}_{3-x}\right]_{0}=20 \mathrm{mM},\left[\mathrm{CH}_{3} \mathrm{COOCH}_{3}\right]_{0}=[\mathrm{THF}]_{0}=1.0 \mathrm{M}$, in hexane.

b $\odot$, living polymerization where $\bar{M}_{n}$ increases proportionally to the monomer conversion, being in good agreement with the calculated value, and the polymers' $\bar{M}_{w} / \bar{M}_{n} \simeq 1.1 ; \bigcirc$, the $\bar{M}_{n}$ increases proportionally to the monomer conversion, but being deviated from the calculated value, and the polymers' $\bar{M}_{w} / \bar{M}_{n} \simeq 1.1 ; \triangle$, the polymers' $\bar{M}_{w} / \bar{M}_{n} \simeq 1.2 ; \times$, non-living polymerization where $\bar{M}_{n}$ is constant or decreases with the monomer conversion.

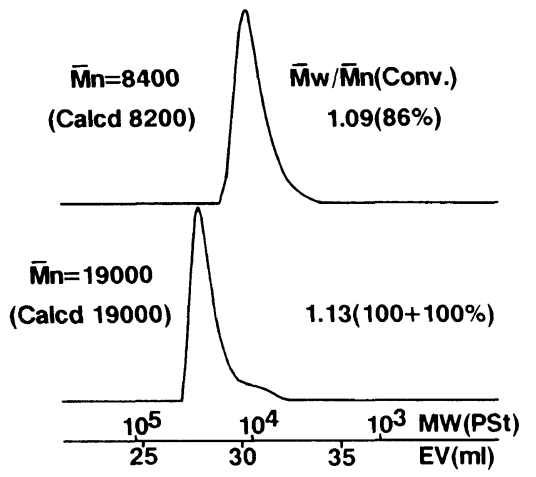

Figure 3. MWDs of poly(TBVE) obtained in the monomer-addition experiment in the polymerization by $1 / \mathrm{Et}_{1.5^{-}}$ $\mathrm{AlCl}_{1.5}$ in the presence of THF $(1.0 \mathrm{M})$ in hexane at $-20^{\circ} \mathrm{C}: \quad[\mathrm{TBVE}]_{0}=0.38+0.38 \mathrm{M} ; \quad[1]_{0}=4.0 \mathrm{mM}$; $\left[\mathrm{Et}_{1.5} \mathrm{AlCl}_{1.5}\right]_{0}=20 \mathrm{mM}$.

further demonstrated by the sequential addition of fresh TBVE to the polymerization reaction mixture. As shown in Figure 3, MWD of the polymer after monomer addition remained as narrow as that for the first-stage polymerization, and it clearly shifted toward the higher molecular weight regions with the progress of the polymerization, except for the minor shoulder in the lower molecular weight regions. These results demonstrate that the living cationic polymerization of TBVE was achieved under such restricted conditions where the polymerization rate was slowed down and growing carbocation was stabilized enough through strong interactions with the added base. However, the minor shoulder in the polymer's MWD obtained after sequential monomer addition might indicate lower stability of the carbocation of TBVE than that of the other vinyl ethers as IBVE.

Using this system $\left([\mathrm{TBVE}]_{0}=3.8 \mathrm{M},[\mathbf{1}]_{0}=\right.$ $2.0 \mathrm{mM},\left[\mathrm{Et}_{1.5} \mathrm{AlCl}_{1.5}\right]_{0}=20 \mathrm{mM}$; solvent: hexane, temperature: $-20^{\circ} \mathrm{C}$, time: $36 \mathrm{~h}$, conv. $=78 \%$ ), living polymers with a molecular weight higher than $10^{5}$ were successfully prepared $\left(\bar{M}_{n}=1.1 \times 10^{5}, \bar{M}_{w} / \bar{M}_{n}=1.11\right)$. The almost quantitative dealkylation $(99.9 \%)$ of tert-butyl groups of poly(TBVE) was accomplished by bubbling dried $\mathrm{HBr}$ gas through the toluene solution at room temperature, which was confirmed by ${ }^{1} \mathrm{H}$ NMR in DMSO- $d_{6}$, to yield poly(vinyl alcohol). The optimum conditions of dealkylation reactions and evaluation of the tacticity of PVA are now under investigation. The softening point of the obtained poly(TBVE) $\left[93-99^{\circ} \mathrm{C}\left(\bar{M}_{w}=2.1 \times\right.\right.$ $\left.\left.10^{4}, \bar{M}_{w} / \bar{M}_{n}=1.08\right)\right]$ was higher than the literature value ${ }^{12}\left[68-79^{\circ} \mathrm{C}\left(\bar{M}_{w}=2.5 \times 10^{4}\right.\right.$, $\bar{M}_{w} / \bar{M}_{n}:$ n.d.)].

\section{Polymerization of Various Alkyl Vinyl Ethers}

To elucidate the reasons for differences in the polymerization behavior between TBVE and IBVE, various alkyl vinyl ethers were polymerized and the effects of the bulkiness 
and/or the shape of alkyl groups were investigated.

Polymerization of NPVE. As a vinyl ether monomer having different types of bulky alkyl groups from TBVE, NPVE was polymerized by $1 / \mathrm{EtAlCl}_{2}$ in the presence of methyl acetate in hexane at $0^{\circ} \mathrm{C}$. According to the Taft's steric parameters Es, ${ }^{13}$ the effective size of neo-pentyl group $(-1.74)$ is similar or somewhat larger than that of tert-butyl group ( -1.54$)$. Here, Es of alkyl groups evaluated based on the hydrolysis rates of $\mathrm{R}-\mathrm{COOC}_{2} \mathrm{H}_{5}$ was used. ${ }^{13}$

Figure 4 shows relationships between the monomer conversion and $\bar{M}_{n}$ or $\bar{M}_{w} / \bar{M}_{n}$ of the obtained poly(NPVE). For comparison, the data of the poly(TBVE) were also quoted from Figure 2. In spite of the bulky pendant group, the living polymerization of NPVE was achieved. $\bar{M}_{n}$ increased almost proportionally to the monomer conversion, though the small deviation from calculated values at high conversions was observed, and MWDs of the polymers obtained were all quite narrow $\left(\bar{M}_{w} / \bar{M}_{n} \leq 1.1\right)$, which is distinct from the behavior of TBVE. The polymerization be-

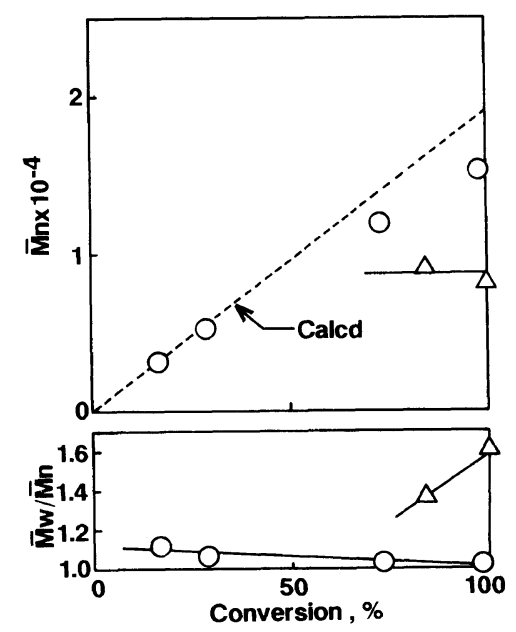

Figure 4. Relationships between monomer conversion and $\bar{M}_{n}$ or $\bar{M}_{w} / \bar{M}_{n}$ of polymers in the polymerization of NPVE $(O)$ and TBVE $(\triangle)$ by $1 / E_{A} A_{C l}$ in the presence of methyl acetate $(1.0 \mathrm{M})$ in hexane at $0^{\circ} \mathrm{C}:[\mathrm{NPVE}]_{0}=$ $0.67 \mathrm{M} ;[\mathrm{TBVE}]_{0}=0.76 \mathrm{M} ;[1]_{0}=4.0 \mathrm{mM} ;\left[\mathrm{EtAlCl}_{2}\right]_{0}=$ $20 \mathrm{mM}$. havior may depend not on the bulkiness of alkyl groups but on the number of branches attached to the $\alpha$-carbon of the side chain.

\section{Polymerization of Butyl Vinyl Ether Isomers.} To further elucidate the effects of the shape of alkyl groups on polymerization behavior, four butyl vinyl ether isomers $\left[\mathrm{CH}_{2}=\mathrm{CH}-\mathrm{OR}\right.$ : $\mathrm{R}=n-\mathrm{C}_{4} \mathrm{H}_{9}$ (NBVE), iso- $\mathrm{C}_{4} \mathrm{H}_{9}$ (IBVE), sec$\mathrm{C}_{4} \mathrm{H}_{9}$ (SBVE), and tert $-\mathrm{C}_{4} \mathrm{H}_{9}$ (TBVE)] were polymerized by the $1 / \mathrm{EtAlCl}_{2}$ initiating system in the presence of methyl acetate in hexane at $0^{\circ} \mathrm{C}$. These butyl vinyl ethers are classified into three groups: primary (NBVE, IBVE), secondary (SBVE), and tertiary (TBVE). In the cases of NBVE and IBVE, the time taken to reach quantitative yield was about $4-7 \mathrm{~h}$, while the polymerization of TBVE and SBVE proceeded up to the quantitative yield within $10 \mathrm{~min}$ (Figure 5). Figure 6 shows relationships between the monomer conversion and $\bar{M}_{n}$ or $\bar{M}_{w} / \bar{M}_{n}$ of the obtained polymers. MWDs of the polymers of NBVE, IBVE, and SBVE, except TBVE were all quite narrow $\left(\bar{M}_{w} / \bar{M}_{n} \sim\right.$ 1.1) and polymers' $\bar{M}_{n}$ were directly proportional to the monomer conversion and in good agreement with the calculated value assuming that one polymer chain is formed per one molecule of cationogen 1. Cosequently, from

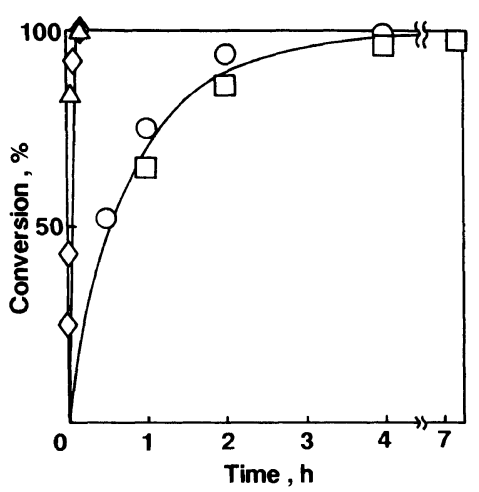

Figure 5. Time-conversion curves for the polymerization of NBVE $(\bigcirc)$, IBVE $(\square)$, SBVE $(\diamond)$, and TBVE $(\triangle)$ by $1 / \mathrm{EtAlCl}_{2}$ in the presence of methyl acetate $(1.0 \mathrm{M})$ in hexane at $0^{\circ} \mathrm{C}$ : $[\text { Monomer }]_{0}=0.76 \mathrm{M} ;[1]_{0}=4.0 \mathrm{mM}$; $[\mathrm{EtAlCl}]_{0}=20 \mathrm{mM}$. 


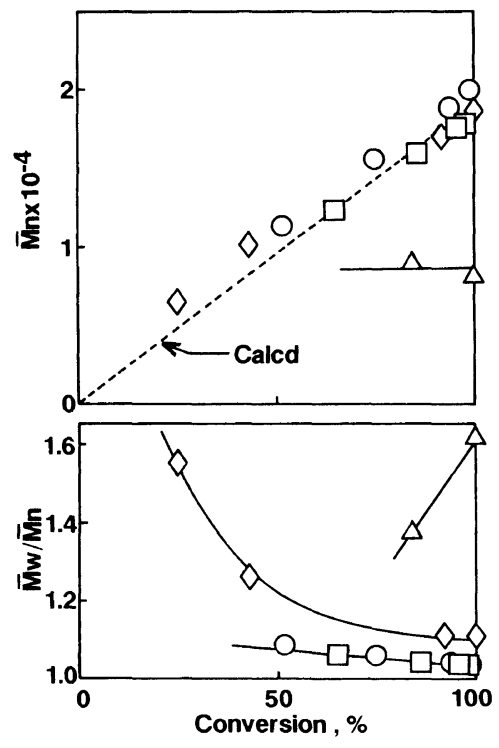

Figure 6. Relationships between monomer conversion and $\bar{M}_{n}$ or $\bar{M}_{w} / \bar{M}_{n}$ of polymers in the polymerization of $\operatorname{NBVE}(\bigcirc), \operatorname{IBVE}(\square)$, SBVE $(\diamond)$, and TBVE $(\triangle)$ by $1 / \mathrm{EtAlCl}_{2}$ in the presence of methyl acetate $(1.0 \mathrm{M})$ in hexane at $0^{\circ} \mathrm{C}:[\text { Monomer }]_{0}=0.76 \mathrm{M} ;[1]_{0}=4.0 \mathrm{mM}$; $[\mathrm{EtAlCl}]_{0}=20 \mathrm{mM}$.

these polymerization results of four butyl vinyl ether isomers, the effects of the shape of side alkyl groups have become clear. That is, by increasing chain branching of alkyl groups, polymerization rates increase and the living nature of the obtained polymers lowers. The difference in the monomer reactivity is thought to depend primarily on an electlon-donating power of the side alkyl groups through the inductive effect, since difference in the nonliving cationic polymerization has been explained based on the relationships between the monomer reactivity ratio and Taft's $\sigma^{*} .{ }^{14,15}$ In addition, the high reactivity of TBVE and the lower stability of its propagating species might be also interpreted as follows: the steric crowding near the growing center weakens the interaction with the added Lewis base. As previously reported, steric environments around the carbonyl group of carboxylate added bases affect remarkably the polymerization rate. ${ }^{16}$
Further inspection of these relationships shows that MWDs of poly(SBVE) obtained were narrow at high conversions, whereas broader especially at lower conversions than those of the polymers of NBVE and IBVE. These results might be explained on the basis of the ratio of the rates between the propagation reaction and initiation reaction. The polymerization rate of SBVE was about 30 times that of NBVE or IBVE, so that too fast propagation reaction relative to the initiation reaction may induce broader MWD of the polymer at lower conversion.

\section{CONCLUSION}

The polymerization behavior of TBVE is quite different from that of other alkyl vinyl ethers. The differences are considered caused not by the bulkiness of substituents but rather by the shape of the branches of the alkyl groups. The effects of the branches on the substituents are as follows: (i) increasing of polymerization rate, (ii) increasing of side reactions as chain transfer reactions. In spite of these unfavorable factors, the living polymerization of TBVE was actually achieved by the use of a weak Lewis acid activator and THF additive at a low temperature.

\section{REFERENCES}

1. S. Aoshima, S. Iwasa, and E. Kobayashi, Polym. J., submitted.

2. S. Aoshima, K. Shachi, and E. Kobayashi, Makromol. Chem., 192, 1759 (1991).

3. S. Aoshima and T. Higashimura, Macromolecules, 22, 1009 (1989); T. Higashimura, M. Sawamoto, and S. Aoshima, Makromol. Chem., Macromol. Symp., 13/14, 457 (1988).

4. S. Okamura, T. Kodama, and T. Higashimura, Makromol. Chem., 53, 180 (1962).

5. K. Fujii and T. Mochizuki, Kobunshi Kagaku, 19, 124 (1962).

6. T. Higashimura, K. Suzuoki, and S. Okamura, Makromol. Chem., 86, 259 (1965).

7. H. Yuki, K. Hatada, and M. Takeshita, J. Polym. Sci. A, 7, 667 (1969).

8. W. H. Watanabe and L. E. Conlon, J. Am. Chem. 
Soc., 79, 2828 (1957).

9. J. Furukawa, E. Kobayashi, S. Nagata, and T. Moritani, J. Polym. Sci., Polym. Chem. Ed., 12, 1799 (1974).

10. S. Aoshima, H. Oda, and E. Kobayashi, J. Polym. Sci., A, Polym. Chem., 30, 2407 (1992); S. Aoshima, H. Onishi, M. Kamiya, K. Shachi, and E. Kobayashi, J. Polym. Sci., A, Polym. Chem., in press.

11. K. Kishimoto, S. Aoshima, and T. Higashimura, Macromolecules, 22, 3877 (1989).

12. L. Fishbein and B. F. Crowe, Makromol. Chem., 48,
221 (1961).

13. R. W. Taft, Jr., "Steric Effects in Organic Chemistry," M. S. Newman, Ed., John Wiley, New York, N.Y., 1963.

14. For a review, T. Higashimura and M. Sawamoto, "Comprehensive Polymer Science," Vol. 3, G. Allen, Ed., Pergamon, Oxford, 1989, p 673.

15. For example, T. Higashimura, J. Masamoto, and S. Okamura, Koubunshi Kagaku, 26, 702 (1968).

16. S. Aoshima, K. Shachi, E. Kobayashi, and T. Higashimura, Makromol. Chem., 192, 1749 (1991). 